Georgia State University

ScholarWorks @ Georgia State University

\title{
The Impact of Adolescent Chronic Pain on Functioning: Disentangling the Complex Role of Anxiety
}

Lindsey L. Cohen

Georgia State University, Ilcohen@gsu.edu

Kevin E. Vowles

Christopher Eccleston

Follow this and additional works at: https://scholarworks.gsu.edu/psych_facpub

Part of the Psychology Commons

\section{Recommended Citation}

Cohen, L. L., Vowles, K. E., \& Eccleston, C. (2010). The impact of adolescent chronic pain on functioning: Disentangling the complex role of anxiety. The Journal of Pain, 11(11), 1039-1046. DOI: 10.1016/ j.jpain.2009.09.009

This Article is brought to you for free and open access by the Department of Psychology at ScholarWorks @ Georgia State University. It has been accepted for inclusion in Psychology Faculty Publications by an authorized administrator of ScholarWorks @ Georgia State University. For more information, please contact scholarworks@gsu.edu. 
Running title: ADOLESCENT CHRONIC PAIN AND ANXIETY

The Impact of Adolescent Chronic Pain on Functioning:

Disentangling the Complex Role of Anxiety

Lindsey L. Cohen ${ }^{1,2}$

Kevin E. Vowles ${ }^{2,3}$

Christopher Eccleston ${ }^{2}$

${ }^{1}$ Department of Psychology, Georgia State University (USA)

${ }^{2}$ Centre for Pain Research, School for Health, University of Bath (UK)

${ }^{3}$ Interdisciplinary Musculoskeletal Pain Assessment and Community Treatment Service, The Haywood Hospital and Keele University (UK)

Corresponding Author: Lindsey L. Cohen, Ph.D., Bath Centre for Pain Research, School for Health, University of Bath, Bath, BA2 7AY, UK; (Ph) +44 (0)1225 384253; (Fx) +44 (0)1225 383 622; (Email) Ilcohen@gsu.edu; (URL address) http://www2.gsu.edu/ wwwpsy/faculty/cohen.htm 


\begin{abstract}
A number of adolescents with chronic pain have clinically significant disability across physical, social, and academic activities, and pain severity only explains a portion of the variance in functioning. Thus, it is important to identify therapeutic options to improve adolescents' functioning. In contrast to studies with adults with chronic pain, research in pediatric pain has not consistently found anxiety to be a good predictor of pain-related disability. The present study evaluated pain, anxiety, and functioning in 222 adolescents with chronic pain. Results indicated that pain was consistently and linearly related to disability across measures of physical and social functioning, school attendance, and physician visits. The relation between anxiety and functioning was complex; increased anxiety was related to poorer physical and social functioning and was related to fewer physician visits, although it was not associated with school attendance. Additional analyses revealed that anxiety serves to moderate the relation between pain and functioning. Specifically, at high anxiety, pain was not related to functioning, but at low anxiety pain consistently predicted disability. In other words, highly anxious adolescents were functioning poorly regardless of the level of pain. The moderating role of anxiety highlights a number of research and clinical possibilities to explore with adolescents with chronic painrelated disability.

Perspective: Data suggest that high anxiety is associated with poor functioning irrespective of pain intensity. At low anxiety, higher pain predicted greater disability. Anxiety is important to assess when investigating potential reasons for pain-related disability.
\end{abstract}

Keywords: Adolescent; Chronic Pain; Disability; Anxiety 
Introduction

A quarter to a third of youth report chronic, persistent, or episodic pain $9,12,14,16,32$ and a clinically significant minority also report associated dysfunction across a range of activities (e.g., physical, social, academic) (e.g., 7,37). Although the severity and duration of pain predicts some of the variance in measures of functioning and quality of life (e.g., ${ }^{17,30}$ ), there are other factors that buffer or exacerbate pain-related disability. Studies with adult patients suggest that psychological variables influence disability above and beyond pain ${ }^{49}$, and anxiety in particular has been found to play a critical role ${ }^{3,34,47,50}$. Paralleling adult chronic pain findings, research with pediatric chronic pain patients suggests that pain intensity and duration only predict a moderate amount of the variance in disability ${ }^{4,11}$, and that psychological factors might help explain disability ${ }^{48}$. Whereas some studies have found positive associations between anxiety and disability in these pediatric patients ${ }^{22,52}$, other studies have not found an anxiety-disability link, particularly when controlling for other variables ${ }^{11,13,21,35,48}$. On the other hand, depression has consistently been found to predict disability in adolescents with chronic pain $4,11,20,22,23$

From a behavioral perspective, chronic pain can lead to avoidance of situations that exacerbate or are believed to exacerbate pain. In turn, the avoidance itself is negatively reinforced if pain is minimized or even unchanged ${ }^{10,50}$. For example, adolescents might avoid school and time spent in social and recreational activities (e.g., sports) in efforts to avoid pain. In fact, the affective aspects (e.g., depression, anxiety, fear of pain) might be the critical factors rather than pain that fuel the avoidance behavior. A cycle might ensue involving anxiety and depression 
driving avoidance, which leads to greater physical and social disability, which further heightens anxiety and depression.

Research with adults support this hypothesis in that anxiety has been shown to heighten sensitivity to pain ${ }^{6}$, is associated with fear of pain, predicts physical complaints beyond the impact of pain ${ }^{27}$, and leads to avoidance of activities and worsening of disability in chronic pain patients ${ }^{29,46}$. Further, treatment targeting anxiety in adults with chronic pain has resulted in reductions in anxiety, as well as improvements in pain and indices of physical and emotional functioning ${ }^{28,51}$. Thus, when anxiety is high, anxiety rather than pain might drive avoidant behavior. On the other hand, in the absence of anxiety, it might be pain itself that leads to avoidance of physical and social events. In other words, whether or not pain symptoms lead to adolescents' physical and social disability might be moderated by anxiety. It should be noted that this pain-anxiety-disability theoretical explanation is largely supported by data with adults, and that anxiety might function differently in youth.

The purpose of this study was to explore this pain-anxiety interplay in relation to physical and social functioning in a sample of young people. It was expected that when adolescents have high anxiety, they would have poor functioning regardless of pain severity. At low anxiety, pain would be linearly related to physical and social disability.

\section{Materials and Methods}

\section{Participants}

The study was approved by the local UK National Health Service ethics committee and all participants consented to participate. Two hundred and twenty-two adolescents from two adolescent chronic pain clinics - an outpatient rheumatology clinic and a residential chronic pain clinic - and their parents participated. On 
average, adolescents were 15 years old $(M=14.8$ years; $S D=1.9$ years; range $=$ 10.9-18.9 years), female (74.6\%), and white European (99.1\%). The adolescents had chronic pain for an average of 4.2 years $(S D=4.1$ years; range $=3$ months 17.5 years) and pain was reportedly experienced in all body parts (43.1\%), a limb (37.3\%), the back (7.7\%), the head (4.8\%), the abdomen (4.3\%), the hip (1\%), or chest (.5\%). Most patients (72.1\%) had non-inflammatory pain (e.g.,low back pain) with a minority (27.9\%) having inflammatory pain (e.g., arthritis).

Parents provided proxy-report of adolescent's pain-related disability. On average, the parents were mothers of the patient (91\%; fathers, $5 \%$; other $4 \%$ ), 43.8 years of age $(S D=6.4$ years), full or part time employed $(67 \%)$, married $(78 \%)$, and in good $(33 \%)$ to very good $(31 \%)$ health.

This sample has been examined in two prior studies to validate the self-report pain-related disability scale ${ }^{7}$ and the parent proxy version ${ }^{8}$. In addition, a study found that a portion of the sample $(\mathrm{N}=110)$ attending a chronic pain clinic did not demonstrate a relation between anxiety and functioning ${ }^{11}$. However, moderation analyses were not conducted. Thus, the current investigation is unique and designed to extend and explain prior findings with these and other adolescents with chronic pain and their parents.

Measures

Pain Intensity. Pain was assessed via a $10 \mathrm{~cm}$ visual analog scale (VAS) querying adolescents about their typical pain over the last week. The extremes of the VAS were anchored with "no pain" (0) and "the worst pain possible" (10). VAS's have been shown to be valid and reliable and recommended as a well-established index of pain intensity ${ }^{5}$. 
Anxiety. To measure anxiety, adolescents completed the Spence Children's Anxiety Scale (SCAS; ${ }^{40,39}$ ). The SCAS contains 44 items (e.g., I have trouble going to school in the morning because I feel nervous or afraid) scored on a 4-point scale ranging from Never (scored 0) to Always (scored 4). Large sample analyses have supported the measure's factor structure and convergent validity ${ }^{39,41}$. Strengths of the SCAS are that it was not created as a downward extension of adult anxiety measures, as was done with other widely-used measures (e.g., Revised Children's Manifest Anxiety Scale ${ }^{36}$; the State-Trait Anxiety Inventory for Children ${ }^{42}$ ), but considered anxiety that is relevant to adolescents. Further, the SCAS measures anxiety that is more consistent with diagnostic systems, such as the DSM ${ }^{1}$, which facilitates communication among health care professionals. The SCAS has consistently demonstrated good reliability (e.g., total score internal consistency Cronbach's alpha .92 and 6-month test-retest correlation .60 ${ }^{39}$ ) and validity (e.g., correlations among other measures of pediatric anxiety range $.71-.81^{31}$ ). In addition, sensitivity analyses has shown that the SCAS differentiates between adolescents with and without anxiety disorders ${ }^{39,53}$. In the current sample, internal consistency was good (Cronbach's alpha .87) and the SCAS total score was significantly correlated with the Bath Adolescent Pain Questionnaire (BAPQ) measures of General Anxiety, .67, and Pain-specific Anxiety, .45, and the BAPQ-Parent version General Anxiety, .47, and BAPQ-P Pain-specific Anxiety, .24 (all p's < .01). Only the SCAS total anxiety score was used in the current study, which reflects an overall general tendency toward panic, fear, obsessive-compulsiveness, and/or diffuse worry.

Functioning. Five diverse and multi-informant indices of functioning were selected. The Bath Adolescent Pain Questionnaire (BAPQ) ${ }^{7}$ is a 61 -item self-report 
survey of adolescents' chronic pain-related functioning across seven areas: physical functioning, social functioning, depression, general anxiety, pain-specific anxiety, family functioning, and development. Adolescents indicate frequency of disability (e.g., I feel distant from my friends; I go to movies concerts, or clubs) from Never (scored 0) to Always (scored 4) scale. The BAPQ has been shown to be valid and reliable ${ }^{7}$ and Cronbach's alpha for the current sample ranged from .80 to .85 . To reduce the number of analyses, the two scales deemed to be most relevant to the current aims were selected: physical functioning and social functioning, which each contained 9 items (scores can range from $0-36$ ). The BAPQ-P ${ }^{8}$ served as a parent proxy measure of adolescents' functioning. The BAPQ-P is identical to the BAPQ, except the stems for the question have been modified (e.g., "My child...").

Psychometrics have been found to be strong ${ }^{8}$ and reliability was good for this sample (Cronbach's alphas .84 - .93). As with the BAPQ, physical functioning and social functioning were examined. School attendance provided a third measure of functioning. Adolescents reported how many school sessions (half days) that they attended on average each week (0-10 half days in a school week). Lastly, adolescents' and parents' report of the number of physician visits over the prior 6 months served as two additional indices of adolescent functioning. Given the longstanding nature of chronic pain in this population, fewer physician visits generally indicate greater physical and social functioning.

\section{Results}

\section{Preliminary Analyses}

Descriptive statistics and Pearson Product Moment (PPM) correlations were used to summarize the study variables. These data indicate that adolescents were reporting moderate to high pain $(M=6.72, S D=2.47)$ on a $0-10$ scale. The average 
anxiety score of $24.78(S D=14.74)$ is higher than means found in non-clinical samples $\left(16.9^{31}, 17.68^{53}, 19.90^{39}, 21.72^{41}\right)$, but lower than a sample of North American children and adolescents diagnosed with an anxiety disorder (35.82 $\left.{ }^{53}\right)$. However, caution should be taken when comparing scores across studies and samples as a number of factors (e.g., demographics, study procedures) might explain apparent differences. Average Self-reported and Parent-report Physical and Social Functioning ranged from $12.46(S D=6.59)$ to $14.43(S D=8.08)$, which falls roughly in the middle of the 0 to 36 possible disability score. In addition, adolescents were missing on average over $1 \frac{1}{2}$ days of school each week (3.44 half days missed) and visiting their physicians 3-4 times over the prior 6 months (Table 1).

Analyses indicated that all measures of functioning were strongly associated (all p's <.01), suggesting that each tapped aspects of disability (Table 2). Pain was positively related to all measures of disability (all p's $<.01$; Table 3 ), and Anxiety was positively correlated with Self- and Parent-report Physical and Social disability (all p's $<.05$ ), but not School Attendance or Self- and Parent-report Physician Visits (Table 3).

\section{Analytic Approach to Primary Analyses}

The test of main effects, moderation, and post-hoc probing of significant interactions was conducted in accord with recommendations ${ }^{2,15}$. Separate regression models were used to test the main effects and interaction of Pain and Anxiety on each of the 7 measures of functioning. To control for potential confounds, Age, Gender, Pain Type (inflammatory vs. non-inflammatory), Pain Duration, and Clinic Site were tested for statistical entry in the first step of the regression model (i.e., $p<.05$ for entry, $p>.10$ for removal). At the second level, the separate main effects for Anxiety and Pain were simultaneously entered. At the third level, the 
Anxiety $x$ Pain interaction term was entered. The Anxiety and Pain variables were each mean-centered prior to creating the interaction term to reduce multicollinearity. Variance inflation factors were all below 2 (range $1.00-1.20$ ), suggesting no significant multicollinearity concerns across measures ${ }^{26}$. Post-hoc probing of significant interactions involved creating high (1 SD above the mean) and low (1 SD below the mean) conditional Anxiety moderator variables and high and low Anxiety $\mathrm{x}$ Pain interaction terms. Post-hoc regressions revealed whether the high and low slopes were significant and provided a regression equation to plot high (1 SD above the mean) and low (1 SD below the mean) Pain scores. As per recommendations, significant main effects were not interpreted when a significant interaction was present $^{24}$; however, the direction of these relations is provided. Primary Analyses

Across all analyses, the significance of variance estimates $\left(r^{2}\right)$ and standardized regression coefficients $(\beta)$ were evaluated. Please see Table 4 for statistical information.

At step one, Age, Gender, Pain Type, and Pain Duration did not account for significant variance in any measure of functioning. The only variable to account for significant variance was Clinic Site, which was related to Self- and Parent-report of Physical and Social Functioning, as well as School Attendance. Across these variables, Clinic Site accounted for $9 \%$ of the variance (range: $8 \%-28 \%$; all $p$ 's < .05; see Table 4). Clinic Site was not related to Self- or Parent-report Physician Visits.

At step 2, Pain and Anxiety together accounted for a significant amount of unique variance in all 7 indices of functioning, averaging $10 \%$ of unique variance (range: $3 \%-16 \%$; all p's <.05; see Table 4). Pain and Anxiety were each inversely 
related to nearly all measures of functioning; as Pain or Anxiety increased, functioning decreased. Controlling for all variables in steps 1 and 2, step 3 revealed that the Pain $x$ Anxiety interaction accounted for an additional $2 \%$ of unique variance on average (range: $2 \%-3 \%$, all p's $<.05$; see Table 4 ) in Self-report and Parentreport Physical Functioning, School Attendance, and Self-report and Parent-report Physician Visits. The interaction term did not account for a significant additional amount of the variance in Self- or Parent-report Social Functioning. Beta weights revealed that the Pain $x$ Anxiety interaction was significant in the same 5 indices of functioning, average $\beta=.16(.14-.19$, all $p$ 's $<.05)$.

Post-hoc probing of the 5 significant interactions revealed that Pain was significantly positively associated with functioning, but only for adolescents with low anxiety. Specifically, at high Anxiety, Pain was not significantly associated with Selfor Parent-report Physical Functioning, School Attendance, or Self- or Parent-report of Physician Visits. However, at low Anxiety, Pain was significantly associated with Self-reported Physical Disability, $\beta=.46, p<.001$; Parent-report Physical Disability, $\beta=.33, p<.001$; School Attendance, $\beta=-.26, p=.003$; Self-report Physician Visits, $\beta=.39, p<.001$; and Parent-report Physician Visits, $\beta=.41, p<.001$. See figures 1 5.

Regarding the two non-significant interactions, there were significant main effects with Pain and Anxiety each separately being associated with Self-report Social Functioning, $\beta=.18, p=.008, \beta=.30, p<.001$, respectively. Anxiety, but not Pain, was significantly related to Parent-report Social Functioning, $\beta=.32, p<.001$. Each of these effects was in the expected direction with greater levels of anxiety and/or pain being associated with greater disruptions in functioning. 
The primary aim of this study was to examine whether anxiety moderates the relations between pain and functioning in adolescents with chronic pain, such that pain only explained significant variance in functioning when anxiety was absent or low. It was hypothesized that at high anxiety, pain would not be associated with physical and social disability. Results supported these hypotheses - at high anxiety, pain severity was not related to functioning in these adolescents with chronic pain. In fact, it appears that when anxiety is high, these adolescents have poor physical functioning, high school absences, and frequent physician visits regardless of severity of pain (see figures 1-5). Thus, it might be that anxiety and not pain is the key contributor to disability when anxiety is high, supporting a behavioral explanation that a reinforcing cycle occurs with anxiety driving avoidance, leading to physical and social disability, which further heightens anxiety. It should be noted that these are cross-sectional data, and it is therefore inappropriate to make causal inferences. Hypothetically, it seems likely that anxiety and disability have reciprocal relations. Alternatively, there could be a third, heretofore unidentified variable, driving these relations.

On the other hand, when anxiety is low, pain is a strong and consistent correlate of functioning in the current sample; at low anxiety, low pain is associated with low disability and high pain with high disability. Consistent with hypotheses, these findings might indicate that in the absence of anxiety, patients are more attuned and responsive to pain. In other words, when anxiety is low, adolescents' engagement in or avoidance of physical events and school might be dictated by their level of pain. As noted above, experimental or longitudinal work is in order to determine the direction of these relations. 
Although anxiety moderated the pain-disability relation across a number of indices, it is interesting that anxiety did not moderate the relation between pain and social functioning. Instead, when controlling for demographics and pain, anxiety was significantly associated with both self-reported and parent-reported social functioning. Thus, anxiety appears to be critical factor influencing whether or not adolescents socialize. Given the cross-sectional nature of the data, it could also be that poorer social functioning heightens anxiety or another variable explains the anxiety-social functioning associations.

When controlling for demographics and anxiety, pain intensity was associated with self-reported but not parent-reported social functioning. Thus, adolescents, but not their parents, might perceive that pain influences their social functioning or that their social disability impacts pain. It could also be that another unknown factor best explains the relation between these variables. Taking together, it appears that parents and adolescents acknowledge an anxiety-social functioning association, but only adolescents report a correlation between their pain and social functioning. It could be that parents perceive that social engagement is related primarily to adolescents' anxiety, and adolescents agree, but adolescents also find that pain is associated with socializing.

In light of the pervasive role of anxiety in these patients, given success in treating pediatric anxiety ${ }^{18,38}$, and findings with adult patients that relief from anxiety might lead to improvements in pain and functioning ${ }^{28}$, anxiety might be a primary target for intervention with adolescents with chronic pain. In addressing anxiety, clinicians might expect that patients with high anxiety will have poor functioning whether pain is low or high; thus, targeting anxiety might be a priority in order to improve physical, social, and academic functioning. When anxiety is under control, it 
might be that the relation between pain and functioning is clarified, which provides additional intervention avenues. Clearly, these are broad suggestions based on group data and professionals should appreciate that tailoring treatment to individual characteristics and circumstances is recommended from an evidence-based practice perspective $^{43}$.

Given the literature linking depression to disability in adolescents with chronic pain ${ }^{4,11,20,22,23}$ and the high co-morbidity and overlap between anxiety and depression (e.g., ${ }^{25}$ ), it is logical to assume that depression might also moderate the pain-disability relation and be explained via the behavioral model linking affective symptoms to avoidance and disability in a feedback cycle. On the other hand, there are important distinctions between anxiety and depression. For example, research has suggested that anxiety might be related to peer and social dysfunction and depression to family dysfunction ${ }^{45}$. Regarding the theoretical model proposed, other ones are viable. For example, it could be that coping (e.g., ${ }^{19}$ ) or parent behavior (e.g., ${ }^{33}$ ) better explain relations between affective symptoms and pain-related disability. These are all empirical questions, which deserve further attention and are beyond the scope of this paper.

As the data are cross-sectional, the five significant interactions could be interpreted as pain moderating the anxiety-functioning relation. Posthoc probing of this alternate hypothesis indicate that when pain is high, anxiety is not related to selfor parent-report physical functioning or school attendance. However, at low pain, anxiety was inversely associated with self- and parent-reported physical functioning and school attendance ( $\beta$ range: .27 - .37; all $p$ 's $<.015)$. These finding suggest that in the absence of pain, anxiety drives disability. In contrast, anxiety predicted selfand parent-reported medical visits at high ( $\beta$ range: .28 - .30; all $p$ 's $<.003)$ but not at 
low pain. Thus, when adolescents with long-standing chronic pain have both high pain and anxiety, they frequent their physician, but when pain is low, anxiety does not influence their decision to seek out medical care. The argument that pain moderates the anxiety-functioning relation deserves additional discussion, but is beyond the scope of this paper.

Interpretive caveats to the findings that anxiety influences the pain-disability relation are in order. First, although the anxiety moderation findings are consistent across a range of indices of functioning, the overall explained variance is low. Thus, it is likely that the pain-anxiety-functioning interactions are complex and further inquiry is in order. For example, the SCAS total score measures global anxiety, and specific indices of social anxiety, anxiety sensitivity, or other fine-grained anxiety measures might provide additional information about how anxiety influences adolescents' pain-related disability. Other limitations are that the sample was demographically homogenous and findings might not extend to adolescents in other locales or with other backgrounds, and that the cross-sectional design does not allow causal or directional inferences. Given the nature of the variables, experimental control is challenging; however, prospective and longitudinal ${ }^{44}$ studies or treatment trials might further tease apart the nature of the relations among chronic pain, anxiety, and functioning.

In summary, we found that pain generally was associated with functioning but relations between anxiety and functioning were complex, which is all consistent with the larger literature in pediatric chronic pain samples. Moderation analyses indicated that when anxiety is high, disability is high irrespective of pain severity, but when anxiety is low, pain is linearly associated with functioning. These findings shed light 
on the role of anxiety in pediatric pain-related functioning, and underscore the need to assess and target anxiety in adolescents with chronic pain and disability. 
Acknowledgements

Support for this research was in part provided by the University of Bath David Parkin Visiting Professorship to Dr. Lindsey Cohen. 


\section{Reference List}

[1] Diagnostic and statistical manual of mental disorders (4th ed.). Arlington, VA US: American Psychiatric Publishing, Inc., 1994.

[2] Aiken LS, West, S. G. Multiple Regression: Testing and Interpreting Interactions. London: Sage Publications, 1991.

[3] Asmundson GJ, Norton PJ, Norton GR. Beyond pain: the role of fear and avoidance in chronicity. Clin Psychol Rev 19:97-119, 1999

[4] Claar RL, Walker LS. Functional assessment of pediatric pain patients: psychometric properties of the functional disability inventory. Pain 121:77-84, 2006

[5] Cohen LL, Lemanek K, Blount RL, Dahlquist LM, Lim CS, Palermo TM, McKenna KD, Weiss KE. Evidence-based assessment of pediatric pain. J Pediatr Psychol 33:939-955; discussion 956-937, 2008

[6] Crombez G, Vlaeyen JW, Heuts PH, Lysens R. Pain-related fear is more disabling than pain itself: evidence on the role of pain-related fear in chronic back pain disability. Pain 80:329-339, 1999

[7] Eccleston C, Jordan A, McCracken LM, Sleed M, Connell H, Clinch J. The Bath Adolescent Pain Questionnaire (BAPQ): development and preliminary psychometric evaluation of an instrument to assess the impact of chronic pain on adolescents. Pain 118:263-270, 2005

[8] Eccleston C, McCracken LM, Jordan A, Sleed M. Development and preliminary psychometric evaluation of the parent report version of the Bath Adolescent Pain Questionnaire (BAPQ-P): A multidimensional parent report instrument to assess the impact of chronic pain on adolescents. Pain 131:48-56, 2007 
[9] El-Metwally A, Salminen JJ, Auvinen A, Kautiainen H, Mikkelsson M. Prognosis of non-specific musculoskeletal pain in preadolescents: a prospective 4-year follow-up study till adolescence. Pain 110:550-559, 2004

[10] Fordyce WEPD. Behavioral Methods for Chronic Pain and IIIness: Mosby Inc, Po Box 628254, Orlando, FL, 32862-8254, 1976.

[11] Gauntlett-Gilbert J, Eccleston C. Disability in adolescents with chronic pain: Patterns and predictors across different domains of functioning. Pain 131:132141,2007

[12] Goodman JE, McGrath PJ. The epidemiology of pain in children and adolescents: a review. Pain 46:247-264, 1991

[13] Goubert L, Eccleston C, Vervoort T, Jordan A, Crombez G. Parental catastrophizing about their child's pain. The parent version of the Pain Catastrophizing Scale (PCS-P): a preliminary validation. Pain 123:254-263, 2006

[14] Hakala P, Rimpela, A., Salminen, J.J., Virtanen, S.M., \& Rimpela, M. . Back, neck, and shoulder pain in Finnish adolescents: National cross sectional surveys. British Medical Journal 325:743-746, 2002

[15] Holmbeck GN. Post-hoc probing of significant moderational and mediational effects in studies of pediatric populations. J Pediatr Psychol 27:87-96, 2002

[16] Huguet A, Miro J. The severity of chronic pediatric pain: an epidemiological study. J Pain 9:226-236, 2008

[17] Hunfeld JA, Passchier J, Perquin CW, Hazebroek-Kampschreur AA, van Suijlekom-Smit LW, van der Wouden JC. Quality of life in adolescents with chronic pain in the head or at other locations. Cephalalgia 21:201-206, 2001 
[18] James A, Soler A, Weatherall R. Cognitive behavioural therapy for anxiety disorders in children and adolescents. Cochrane Database Syst Rev CD004690, 2005

[19] Kaczynski KJ, Claar RL, Logan DE. Testing gender as a moderator of associations between psychosocial variables and functional disability in children and adolescents with chronic pain. Journal of Pediatric Psychology 111,2008

[20] Kashikar-Zuck S, Goldschneider KR, Powers SW, Vaught MH, Hershey AD. Depression and functional disability in chronic pediatric pain. Clin J Pain $17: 341-349,2001$

[21] Kashikar-Zuck S, Lynch AM, Slater S, Graham TB, Swain NF, Noll RB. Family factors, emotional functioning, and functional impairment in juvenile fibromyalgia syndrome. Arthritis Rheum 59:1392-1398, 2008

[22] Kashikar-Zuck S, Parkins IS, Graham TB, Lynch AM, Passo M, Johnston M, Schikler KN, Hashkes PJ, Banez G, Richards MM. Anxiety, mood, and behavioral disorders among pediatric patients with juvenile fibromyalgia syndrome. Clin J Pain 24:620-626, 2008

[23] Kashikar-Zuck S, Vaught MH, Goldschneider KR, Graham TB, Miller JC. Depression, coping, and functional disability in juvenile primary fibromyalgia syndrome. J Pain 3:412-419, 2002

[24] Keppel G. Design and analysis: A researcher's handbook (3rd ed.). Englewood Cliffs, NJ US: Prentice-Hall, Inc, 1991.

[25] Kotsopoulos S. Phenomenology of anxiety and depressive disorders in children and adolescents. The Psychiatric Clinics Of North America 12:803-814, 1989 
[26] Kutner MH, Nachtsheim CJ, Neter J. Applied Linear regression Models. New York: McGraw-Hill Irwin, 2004.

[27] McCracken LM, Faber SD, Janeck AS. Pain-related anxiety predicts nonspecific physical complaints in persons with chronic pain. Behav Res Ther $36: 621-630,1998$

[28] McCracken LM, Gross, R. T. The Role of Pain-Related Anxiety Reduction in the Outcome of Multidisciplinary Treatment for Chronic Low Back Pain: Preliminary Results. Journal of Occupational Rehabilitation 8:179-189, 1998

[29] McCracken LM, Keogh E. Acceptance, mindfulness, and values-based action may counteract fear and avoidance of emotions in chronic pain: an analysis of anxiety sensitivity. J Pain 10:408-415, 2009

[30] Merlijn VP, Hunfeld JA, van der Wouden JC, Hazebroek-Kampschreur AA, Koes BW, Passchier J. Psychosocial factors associated with chronic pain in adolescents. Pain 101:33-43, 2003

[31] Muris P, Merckelbach H, Ollendick T, King N, Bogie N. Three traditional and three new childhood anxiety questionnaires: their reliability and validity in a normal adolescent sample. Behav Res Ther 40:753-772, 2002

[32] Perquin CW, Hazebroek-Kampschreur AA, Hunfeld JA, Bohnen AM, van Suijlekom-Smit LW, Passchier J, van der Wouden JC. Pain in children and adolescents: a common experience. Pain 87:51-58, 2000

[33] Peterson CC, Palermo TM. Parental reinforcement of recurrent pain: the moderating impact of child depression and anxiety on functional disability. Journal of Pediatric Psychology 29:331-341, 2004 
[34] Plehn K, Peterson, R. A., Williams, D. A. Anxiety Sensitivity: Its Relationship to Functional Status in Patients with Chronic Pain Journal of Occupational Rehabilitation 8:213-222, 1998

[35] Reid GJ, Lang BA, McGrath PJ. Primary juvenile fibromyalgia: psychological adjustment, family functioning, coping, and functional disability. Arthritis Rheum 40:752-760, 1997

[36] Reynolds CR, Richmond BO. What I think and feel: a revised measure of children's manifest anxiety. Journal Of Abnormal Child Psychology 6:271-280, 1978

[37] Roth-Isigkeit A, Thyen U, Stoven H, Schwarzenberger J, Schmucker P. Pain among children and adolescents: restrictions in daily living and triggering factors. Pediatrics 115:e152-162, 2005

[38] Silverman WK, Pina AA, Viswesvaran C. Evidence-based psychosocial treatments for phobic and anxiety disorders in children and adolescents. J Clin Child Adolesc Psychol 37:105-130, 2008

[39] Spence SH. A measure of anxiety symptoms among children. Behav Res Ther $36: 545-566,1998$

[40] Spence SH. Structure of anxiety symptoms among children: a confirmatory factor-analytic study. J Abnorm Psychol 106:280-297, 1997

[41] Spence SH, Barrett PM, Turner CM. Psychometric properties of the Spence Children's Anxiety Scale with young adolescents. J Anxiety Disord 17:605625, 2003

[42] Spielberger CD, Gorsuch PL, Lushene RE. Manual for the State-Trait Anxiety Inventory. Palo Alto, California: Consulting Psychologist Press, 1970. 
[43] Spring B. Evidence-based practice in clinical psychology: what it is, why it matters; what you need to know. J Clin Psychol 63:611-631, 2007

[44] Stanford EA, Chambers CT, Biesanz JC, Chen E. The frequency, trajectories and predictors of adolescent recurrent pain: a population-based approach. Pain 138:11-21, 2008

[45] Starr LR, Davila J. Differentiating interpersonal correlates of depressive symptoms and social anxiety in adolescence: implications for models of comorbidity. Journal Of Clinical Child And Adolescent Psychology: The Official Journal For The Society Of Clinical Child And Adolescent Psychology, American Psychological Association, Division 53 37:337-349, 2008

[46] Stewart SH, Asmundson GJ. Anxiety sensitivity and its impact on pain experiences and conditions: a state of the art. Cogn Behav Ther 35:185-188, 2006

[47] Strahl C, Kleinknecht RA, Dinnel DL. The role of pain anxiety, coping, and pain self-efficacy in rheumatoid arthritis patient functioning. Behav Res Ther $38: 863-873,2000$

[48] Tsao JC, Meldrum M, Kim SC, Zeltzer LK. Anxiety sensitivity and health-related quality of life in children with chronic pain. J Pain 8:814-823, 2007

[49] Turk DC, Okifuji A. Psychological factors in chronic pain: evolution and revolution. J Consult Clin Psychol 70:678-690, 2002

[50] Vlaeyen JW, Linton SJ. Fear-avoidance and its consequences in chronic musculoskeletal pain: a state of the art. Pain $85: 317-332,2000$

[51] Vowles KE, Gross RT. Work-related beliefs about injury and physical capability for work in individuals with chronic pain. Pain 101:291-298, 2003 
[52] Walker LS, Greene JW. The functional disability inventory: measuring a neglected dimension of child health status. J Pediatr Psychol 16:39-58, 1991 [53] Whiteside SP, Brown AM. Exploring the utility of the Spence Children's Anxiety Scales parent- and child-report forms in a North American sample. J Anxiety Disord 22:1440-1446, 2008 
Figure 1. BAPQ Self-report Physical Functioning as a function of Anxiety and Pain 1 standard deviation above or below the mean for each predictor.

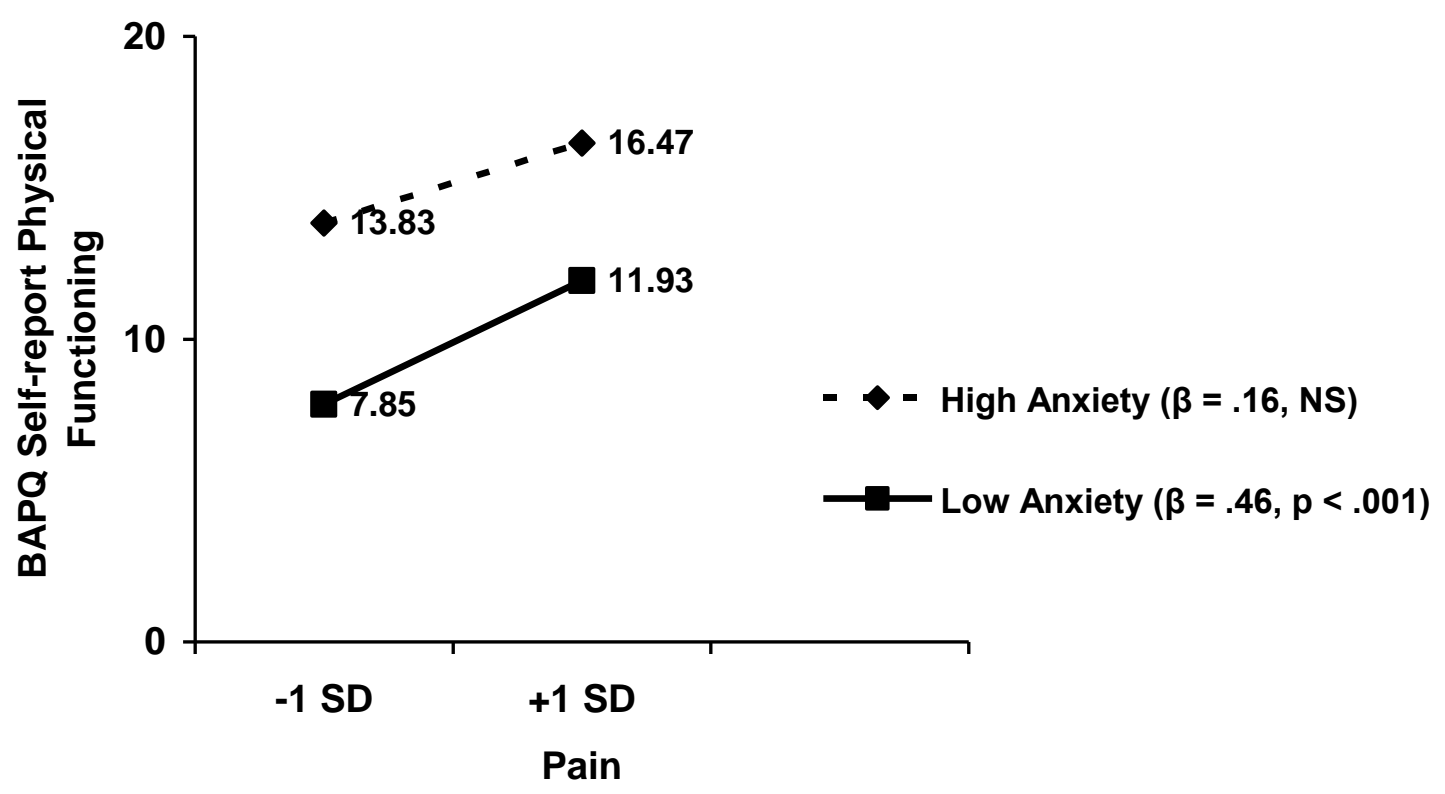


Figure 2. BAPQ-P Parent-report Physical Functioning as a function of Anxiety and Pain 1 standard deviation above or below the mean for each predictor.

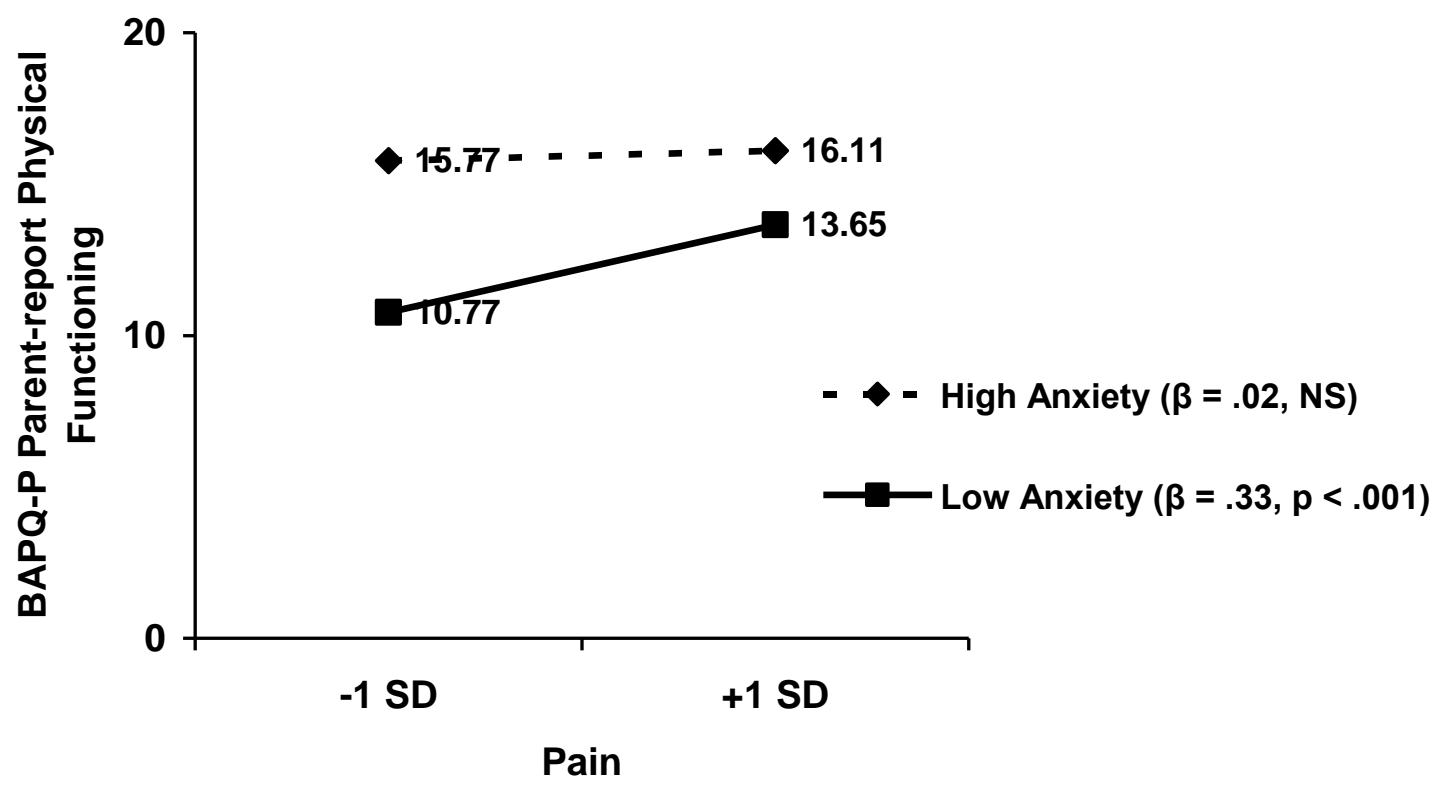


Figure 3. School Attendance as a function of Anxiety and Pain 1 standard deviation above or below the mean for each predictor.

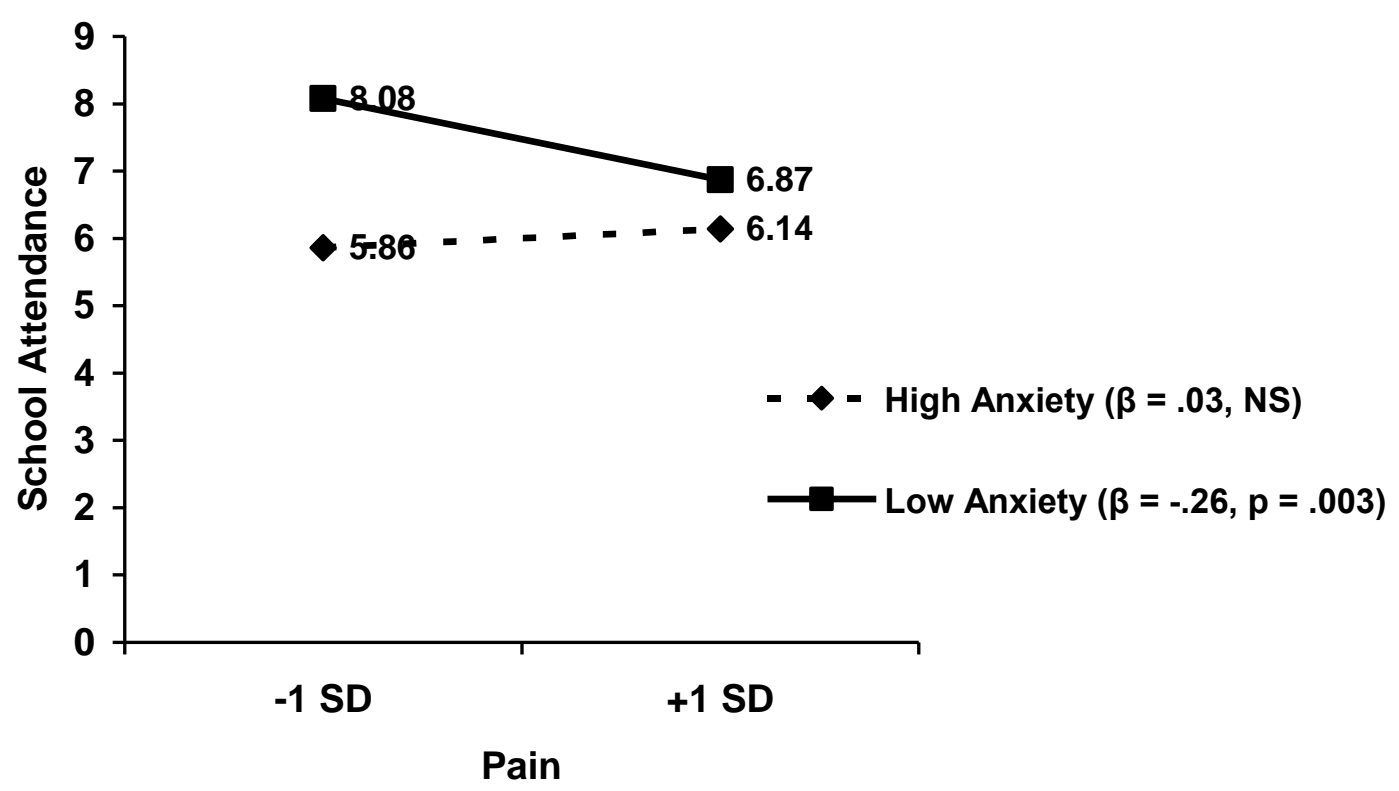


Figure 4. Self-report Physician Visits as a function of Anxiety and Pain 1 standard deviation above or below the mean for each predictor.

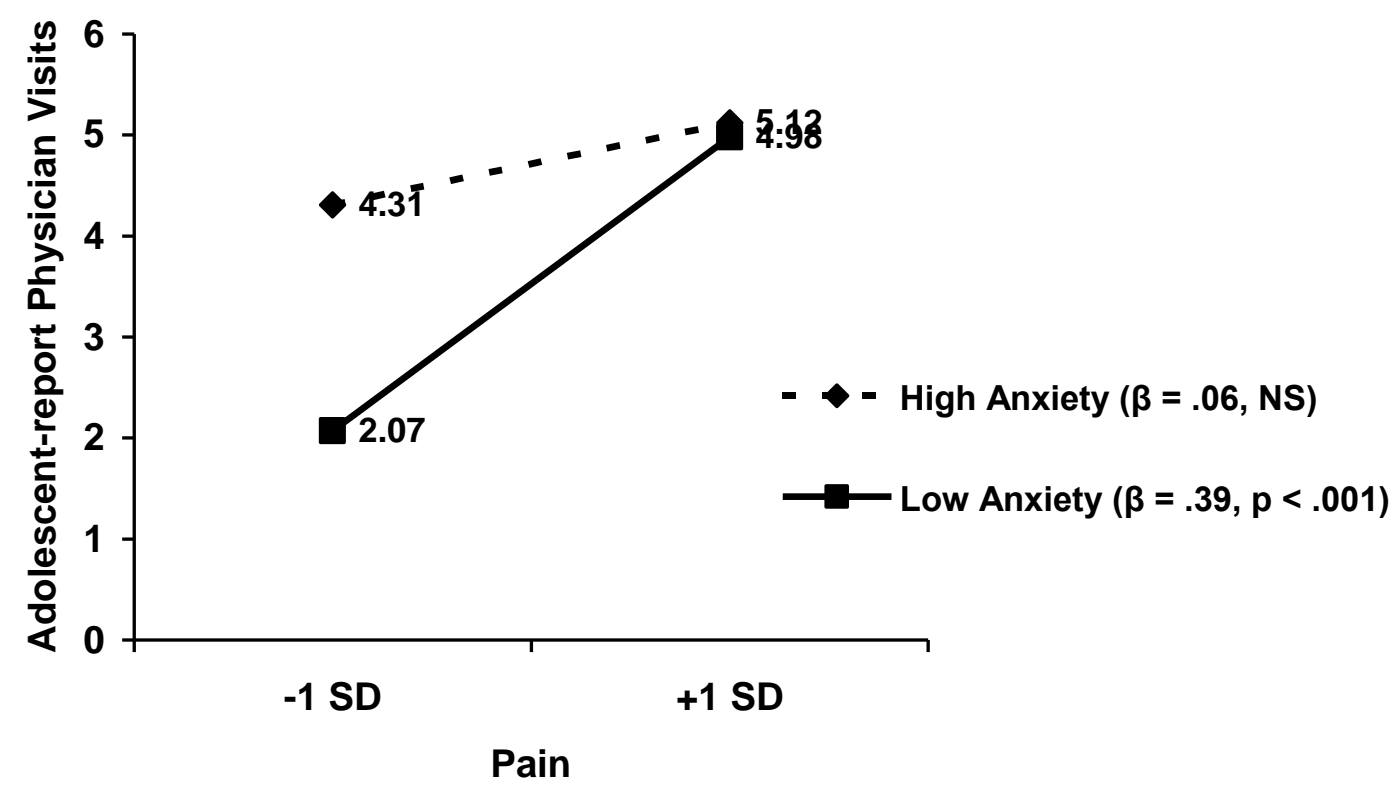


Figure 5. Parent-report Physician Visits as a function of Anxiety and Pain 1 standard deviation above or below the mean for each predictor.

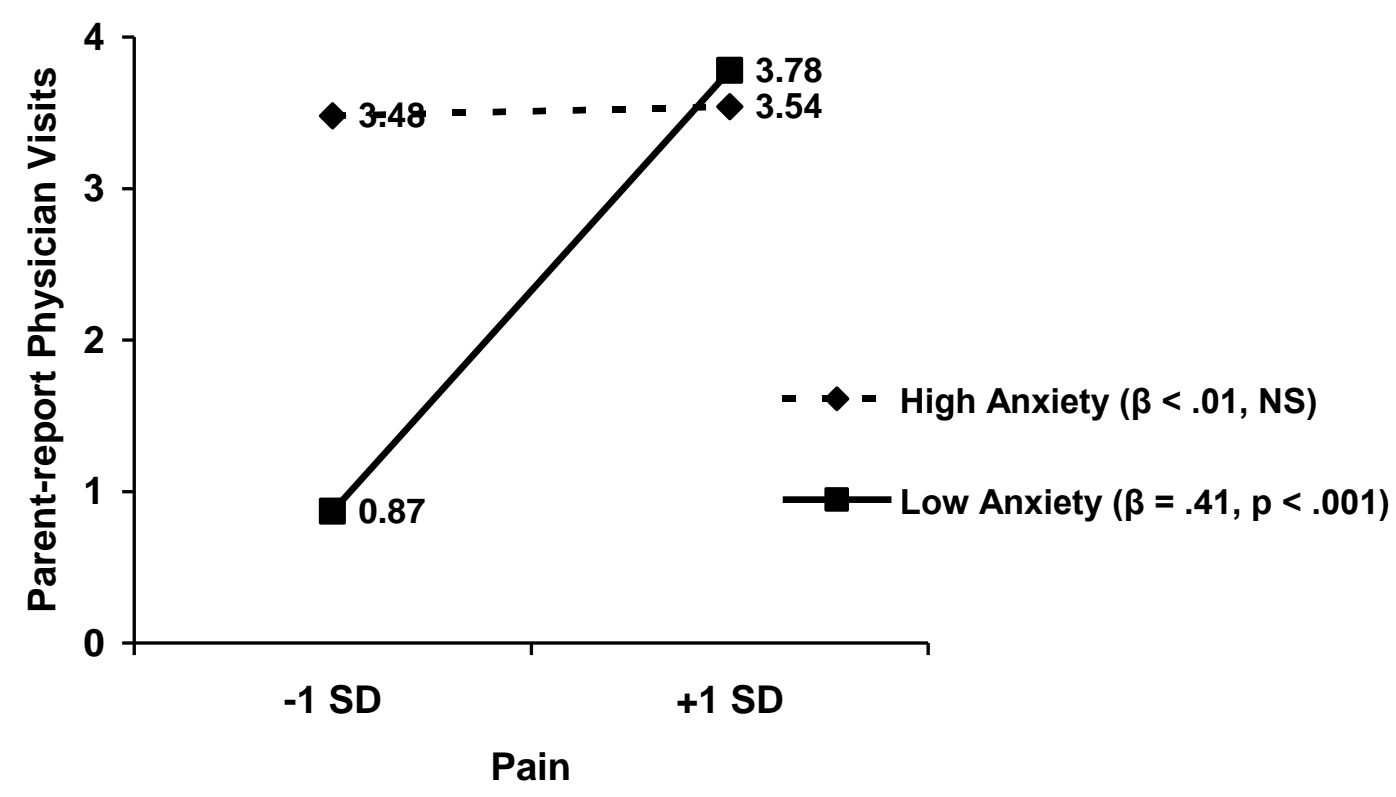


Table 1

Descriptive statistics for study measures

\begin{tabular}{lccc}
\hline Variable & Mean & $S D$ & Range \\
\hline Pain & 6.79 & 2.47 & $0-10$ \\
Anxiety & 24.78 & 14.74 & $2-69$ \\
BAPQ Self-report Physical Functioning & 13.15 & 8.35 & $0-36$ \\
BAPQ Self-report Social Functioning & 12.46 & 6.59 & $1-32$ \\
BAPQ-P Parent-report Physical Functioning & 14.43 & 8.08 & $1-34$ \\
BAPQ-P Parent-report Social Functioning & 14.34 & 7.72 & $0-34$ \\
School Attendance & 6.56 & 4.14 & $0-11$ \\
Self-report Physician Visits & 3.63 & 6.55 & $0-72$ \\
Parent-report Physician Visits & 3.93 & 6.38 & $0-72$ \\
\hline
\end{tabular}


Table 2

Correlations among measures of functioning

\begin{tabular}{|c|c|c|c|c|c|c|}
\hline & 1. & 2. & 3. & 4. & 5. & 6. \\
\hline $\begin{array}{l}\text { 1, BAPQ Physical Functioning } \\
\text { 2. BAPQ Social Functioning }\end{array}$ & $.50^{\star *}$ & & & & & \\
\hline 3. BAPQ-P Physical Functioning & $.84^{* *}$ & $.42^{\star *}$ & & & & \\
\hline 4. BAPQ-P Social Functioning & $.42^{* *}$ & $.70^{* *}$ & $.48^{\star *}$ & & & \\
\hline 5. School Attendance & $-.54^{\star *}$ & $42^{\star *}$ & $-.51^{* \star}$ & $-.43^{* *}$ & & \\
\hline 6. Self-report Physician Visits & $.25^{\star *}$ & $23^{* *}$ & $.24^{* *}$ & $.24^{* *}$ & $-.29^{\star \star}$ & \\
\hline 7. Parent-report Physician Visits & $22^{* *}$ & $20^{* *}$ & $20^{* *}$ & $.20^{\star *}$ & $-.26^{* *}$ & $.93^{*}$ \\
\hline
\end{tabular}


Table 3

Correlations among predictor, moderator, and dependent variables

\begin{tabular}{llc}
\hline & Pain & Anxiety \\
\hline Anxiety & $.23^{\star *}$ & \\
BAPQ Self-report Physical Functioning & $.46^{* *}$ & $.26^{\star *}$ \\
BAPQ Self-report Social Functioning & $.31^{\star *}$ & $.35^{\star *}$ \\
BAPQ-P Parent-report Physical Functioning & $.32^{* *}$ & $.18^{\star}$ \\
BAPQ-P Parent-report Social Functioning & $.24^{\star *}$ & $.33^{\star *}$ \\
School Attendance & $-.30^{\star *}$ & -.12 \\
Self-report Physician Visits & $.23^{* *}$ & -.10 \\
Parent-report Physician Visits & $.23^{* *}$ & -.09 \\
\hline
\end{tabular}

${ }^{*} p<.05 ;{ }^{* *} p<.01$ 
Table 4

Regression Analyses: Pain, Anxiety, and Pain x Anxiety as Predictors of Functioning

\begin{tabular}{|c|c|c|c|c|}
\hline Predictor & $\Delta R^{2}$ & Cumulative $R^{2}$ & Beta & $p \leq$ \\
\hline \multicolumn{5}{|c|}{ BAPQ Self-report Physical Functioning } \\
\hline Step 1 & .10 & .10 & & .001 \\
\hline Clinic Site & & & .31 & .001 \\
\hline Step 2 & .16 & .26 & & .001 \\
\hline Pain & & & .35 & .001 \\
\hline Anxiety & & & .17 & .004 \\
\hline Step 3 & .02 & .28 & & .023 \\
\hline Pain x Anxiety & & & -.15 & .023 \\
\hline \multicolumn{5}{|c|}{$B A P Q$ Self-report Social Functioning } \\
\hline Step 1 & .11 & .11 & & .001 \\
\hline Clinic Site & & & .33 & .001 \\
\hline Step 2 & .14 & .25 & & .001 \\
\hline Pain & & & .18 & .008 \\
\hline Anxiety & & & .30 & .001 \\
\hline Step 3 & $<.01$ & .25 & & Ns \\
\hline Pain $x$ Anxiety & & & -.02 & Ns \\
\hline \multicolumn{5}{|c|}{ BAPQ-P Parent-report Physical Functioning } \\
\hline Step 1 & .09 & .09 & & .001 \\
\hline Clinic Site & & & .30 & .001 \\
\hline Step 2 & .07 & .16 & & .001 \\
\hline Pain & & & .21 & .004 \\
\hline Anxiety & & & .12 & .12 \\
\hline Step 3 & .02 & .18 & & .036 \\
\hline Pain x Anxiety & & & -.15 & .030 \\
\hline \multicolumn{5}{|c|}{ BAPQ-P Parent-report Social Functioning } \\
\hline Step 1 & .08 & .08 & & .001 \\
\hline Clinic Site & & & .27 & .001 \\
\hline Step 2 & .13 & .21 & & .001 \\
\hline Pain & & & .13 & Ns \\
\hline Anxiety & & & .32 & .001 \\
\hline Step 3 & $<.01$ & .21 & & $\mathrm{Ns}$ \\
\hline Pain x Anxiety & & & -.03 & Ns \\
\hline \multicolumn{5}{|c|}{ School Attendance } \\
\hline Step 1 & .28 & .28 & & .001 \\
\hline Clinic Site & & & -.53 & .001 \\
\hline Step 2 & .03 & .31 & & .044 \\
\hline Pain & & & -.15 & .033 \\
\hline Anxiety & & & -.061 & $\mathrm{Ns}$ \\
\hline Step 3 & .02 & .32 & & .043 \\
\hline Pain x Anxiety & & & .14 & .043 \\
\hline
\end{tabular}


Step 2

Self-report Physician Visits

Pain

.08

.08

.001

Anxiety

Step 3

Pain $x$ Anxiety

.02

.10

.27

.001

$\begin{array}{ll}. .16 & .032\end{array}$

$-.16$

.046

Parent-report Physician Visits

Step 2

.08

..08

.001

Pain

Anxiety

Step 3

.03

.11

.001

$-.16$

.030

Pain x Anxiety

Note: In Step 1 of each equation, Age, Gender, and Clinic Site were tested for entry and retained if significant. In Self-report Physician visits and Parent-report Physician visits, none of the covariates were significant or retained. 